\title{
Development of a Nonlinear Dependence for Determining the Stress-Strain State of the Pipeline-Composite Bandage System
}

\author{
Robert A. Ramazanov ${ }^{1}$, Igor F. Kantemirov ${ }^{1}$, Denis A. Gulin ${ }^{1}$, Indira F. Makhmudova ${ }^{1}$, and Zulfiya F. Ismagilova ${ }^{2}$ \\ ${ }^{1}$ Ufa State Petroleum Technological University, RU-450062, Ufa, Republic of Bashkortostan, Russian Federation \\ ${ }^{2}$ Almetyevsk state oil institute, RU-423450, Almetyevsk, Republic of Tatarstan, Russian Federation
}

\begin{abstract}
The range of applications of polymeric materials in the oil and gas industries is expanding every year. For example, at present, a number of industrial enterprises are engaged in the production of various tape polymer composite structures that are used to repair pipelines. They are widely used due to the significant advantages of polymeric materials over steel such as low costs, low weight, corrosion resistance and strength. Moreover, most of the operated pipelines are about to reach their standard service life. In the course of technical diagnostics, a significant number of defects of mechanical origin from external influences are constantly revealed. Repair work on pipelines must fully restore the bearing capacity of the site. Therefore, the use of polymer materials for pipeline repair is an important task. Here, we propose to use polymer composite bandages, which will increase the overhaul period. However, a coherent methodology for choosing a material and calculating the required thickness of this structure is not available in the literature, and, therefore, the purpose of this work was to develop such a methodology, as well as to assess the stress-strain state of pipeline-bandage systems. The method presented in this work takes into account the possible anisotropy of the shroud material in the longitudinal and transverse directions and the possibility of plastic deformation of the pipeline material in the annular direction. This work is based on the following assumptions: (a) bilinear dependence of stress on deformation for steel; (b) plastic deformations of the band material are absent; and (3) absolute adhesion between the pipeline and the band. The paper presents the analysis of the market of polymeric materials for pipeline repair, their key properties, and the minimum thickness of the band made of these materials was calculated for various values of the stress concentration coefficient.
\end{abstract}

\section{Introduction}

In modern days, new main pipelines are built much less frequently than at the end of the 20th century. As a result, the bulk of the pipelines were produced more than 20 years ago, and, hence, amount of work on repair and reconstruction of main pipeline facilities constantly increases.

Long-term operation of pipelines inevitably leads to aging and, therefore, to defects resulting in a marked decrease in the load bearing capacity of pipeline structures. The defects can be divided into repairable and non-repairable ones [1].

Analysis of the diagnostics data showed that most of the defects are of mechanical origin, with "metal loss" type defects being the most common ones. Stress corrosion of pipe metal is also a harmful process. However, timely repair allows reducing negative impacts of the aforementioned factors on the pipeline system.

In ref. [2], a study of the stress-strain state and the assessment of the strength in the zones of dents on the pipes of technological pipelines were reported. The coefficients of the concentration of stresses and strains have been determined using computer modeling for both elastic and elastoplastic nature of local deformations of materials in the mechanical defect zone. The ultimate deformation and the strength conditions, which ensure the reliability of technological pipelines in the presence of defects of mechanical origin, were estimated.

In work [3], the destruction of a pipeline with a corrosion defect was modeled. For steel 19G, a mathematical model of elastoplastic deformation of metals obtained earlier by the same authors was used and a set of practical recommendations was obtained.

In ref.[4], the stress-strain state of a pipeline section with a defect during repair with a composite coupling was investigated. It was shown that the circumferential stresses along the pipe axis in the repaired section, on average, decreased by half. Calculations were validated using field tests of composite couplings.

To reduce the time for repair work on local defects in the pipe metal, it was proposed to use composite reinforcing bands, which are already used to increase the bearing capacity of a pipeline section, for example, in cramped conditions with a forcedly reduced protective zone [5]. Their use requires calculations with the «installation before operation» method and the design scheme shown in Figure 1.

In this case, the bandage is mounted on a welded and insulated pipe string. The material of the bandage is subjected to tensile loads. The initial data are the 
strength properties of the bandage material, the value of the tension force and the design value of the working pressure in the pipeline. After the calculation is completed, we obtain the thickness of the band, which will provide the necessary increase in the bearing capacity of the pipeline.

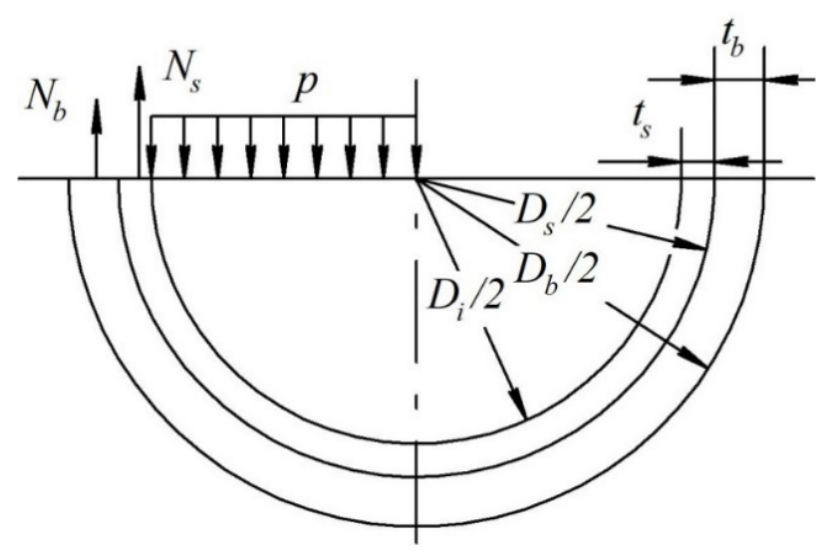

Fig. 1. Equal balance of a half-ring cut from a pipe under the internal pressure (to increase the bearing capacity of the pipeline).

In this case, the bandage is mounted on a welded and insulated pipe string. The material of the bandage is subjected to tensile loads. The initial data are the strength properties of the bandage material, the value of the tension force and the design value of the working pressure in the pipeline. After the calculation is completed, we obtain the thickness of the band, which will provide the necessary increase in the bearing capacity of the pipeline.

Mounting the bandage according to the «on operated pipeline» method provides a completely different operation of the «bandage-pipe» system. The bandage also stretches, but, at the same time, it exerts a compressive force on the pipeline, due to which turning pipeline in an operating mode becomes possible. The design scheme is shown in Figure 2.

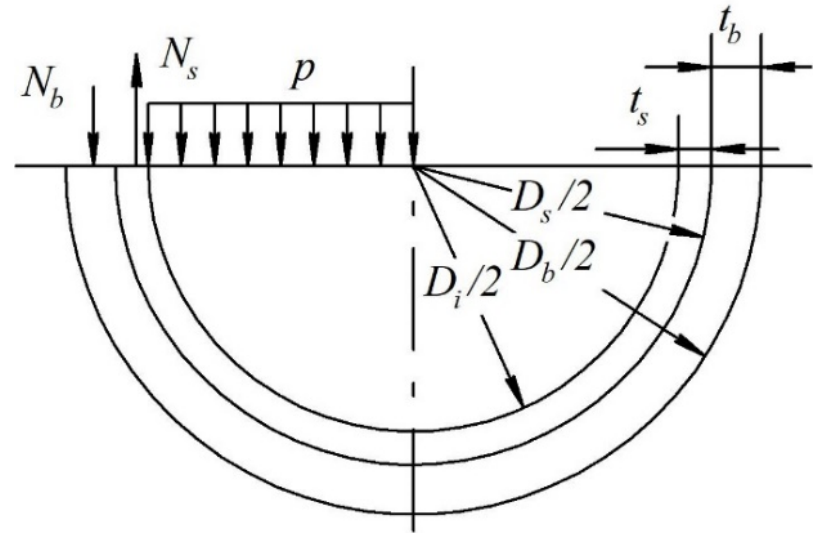

Fig. 2. Equal balance of a half-ring cut from a pipe under the action of internal pressure (during repairing a pipeline section).

The purpose of the calculation is to ensure the safety of the operation of the main pipeline in the case, when a bandage is applied using the second method. The direct result of the strength calculation is a certain value of the minimum thickness of a band made of a specific material with known strength. In addition, the geometrical properties of the pipeline, the type and size of the defect and the minimum pressure that the pipeline must withstand for further operation should be available.

\section{Theory}

Let us consider the equal balance of the half-ring of the "pipeline-bandage» system under the action of internal pressure (during the repair of a pipeline section) in the annular direction, which will be described by the following expression:

$$
\sigma_{2 s} \cdot t_{s}-\sigma_{2 b} \cdot t_{b}=\frac{p D_{i}}{2} .
$$

where $\sigma_{2 s}-$ circular stress in steel, $\mathrm{MPa}$;

$t_{s}$ - wall thickness, m;

$\sigma_{2 b}$ - circular stress in the material of the band, MPa;

$t_{b}$ - bandage thickness, $\mathrm{m}$;

$p$ - internal pressure in the pipeline, $\mathrm{MPa}$;

$D_{i}$ - internal diameter of the pipeline, $\mathrm{m}$.

Circular stresses arising at the site of the defect are proposed to be taken into account using the stress concentrator factor:

$$
\sigma_{2 s}=\alpha_{\sigma} \cdot \frac{p D_{i}}{2}
$$

where $\alpha_{\sigma}$ - stress concentration factor.

The stress concentration factor itself is calculated depending on the type of defect (corrosion pits, mechanical marks, scratches, cuts and scuffs, characterized by the length $\mathrm{l}$, width $\mathrm{d}$, depth $\mathrm{h}$ and radius of curvature at the vertex $\rho$ for a pipe with wall thickness t s) [6].

It is proposed to calculate the thickness of the band, or rather the number of layers of the wound material, depending on its strength characteristics. The permissible stress value in the band is defined as the elastic limit of the band, taking into account the stresses arising during winding. As a result, the following ratio was obtained for the number of layers of the bandage:

$$
n=\frac{p D_{i}}{2} \cdot \frac{\alpha_{\sigma}-1}{\sigma_{u 2 b} t_{b 0}-N} .
$$

where $n$ - number of layers;

$t_{b 0}$ - thickness of the bandage layer;

$\sigma_{u 2 b}$ - elastic strength of the band to the circular direction;

$N$ - tension force of rolled materials.

The resulting value must be rounded up to prevent overvoltage in the cross section of the band material.

To assess the real stress-strain state of the pipelinebandage system, it is proposed to add the following to equation (1) and, at a known value of the bandage thickness, evaluate the work of the steel and the bandage in the longwise and circular directions.

The material of the band is considered as a nonplastic material, then its properties obey Hooke's law. It 
is also assumed that the steel in the longwise direction does not achieve plastic deformation. With absolute adhesion under operating conditions, the deformations of the pipe and the band are equal to each other, both in the longwise and circular direction. Let us express the deformation in the circular direction:

$$
\varepsilon_{2}=\frac{1-v_{12 b} v_{21 b}}{E_{2 b}} \cdot \sigma_{2 b}-\frac{v_{12 b}}{E_{0 s}} \cdot\left(\sigma_{1 s}-v_{0 s} \cdot \sigma_{2 s}\right) .
$$

where $E_{2 b}-$ Young's modulus of the anisotropic material of the band in the circular direction, MPa;

$v_{21 b}$ - Poisson's ratio from the action of the circular stress in the longwise direction of the anisotropic material of the band;

$v_{12 b}$ - Poisson's ratio from the action of longwise stress in the circular direction of the anisotropic material of the band.

$E_{0 \mathrm{~s}}-$ Young's modulus of steel in the elastic area, MPa; $v_{0 s}$ - Poisson's ratio of steel in the elastic area.

The average normal stress of steel in a plane stress state does not take into account the influence of the radial component. Average linear deformation is related to the average normal stress by the ratio of bulk elasticity.

In the framework of the deformation theory of plasticity, the elastoplastic deformation of a pipe can be described by the following equality:

$$
2 \sigma_{2 s}-\sigma_{1 s}=2 \cdot \frac{\sigma_{i s}}{\varepsilon_{i s}} \cdot\left(\varepsilon_{2}-\frac{1-2 v_{0 s}}{E_{0 s}} \cdot \frac{\sigma_{1 s}+\sigma_{2 s}}{3}\right) \text {. }
$$

where $\sigma_{i s}$ - intensity of normal stresses in steel, MPa; $\varepsilon_{i s}$ - the intensity of linear deformations of steel.

The intensity of normal stresses in steel is described by the following expression:

$$
\sigma_{i s}=\sqrt{\sigma_{1 s}^{2}+\sigma_{2 s}^{2}-\sigma_{1 s} \sigma_{2 s}} \text {. }
$$

Longwise stress in the pipeline from the action of internal pressure and temperature difference is determined as:

$$
\sigma_{1 s}=v_{s} \frac{p D_{i}}{2 t_{s}}-\alpha E_{s} \Delta t \pm \frac{E_{s}\left(D_{i}+2 t_{s}\right)}{2 \rho},
$$

where $v_{s}$ - variable Poisson's ratio of steel;

$E_{s}$ - variable Young's modulus of steel, $\mathrm{MPa}$;

$\alpha$ - coefficient of linear expansion of pipe metal, $\mathrm{deg}^{-1}$;

$\Delta t$ - the calculated temperature difference, taken as positive when heated, ${ }^{\circ} \mathrm{C}$;

$\rho$ - the minimum radius of elastic bending of the pipeline axis, $m$.

For steel, the variable Poisson's ratio and the variable Young's modulus are calculated using the well-known formulas [7]:

$$
\begin{aligned}
& v_{s}=\frac{\frac{1}{2}-\frac{1-2 v_{0 s}}{3 E_{0 s}} \cdot \frac{\sigma_{i s}}{\varepsilon_{i s}}}{1+\frac{1-2 v_{0 s}}{3 E_{0 s}} \cdot \frac{\sigma_{i s}}{\varepsilon_{i s}}}, \\
& E_{s}=\frac{\sigma_{i s} / \varepsilon_{i s}}{1+\frac{1-2 v_{0 s}}{3 E_{0 s}} \cdot \frac{\sigma_{i s}}{\varepsilon_{i s}}},
\end{aligned}
$$

Let us take the «stress-strain» diagram of pipeline steel approximated to bilinear dependence (Figure 3).

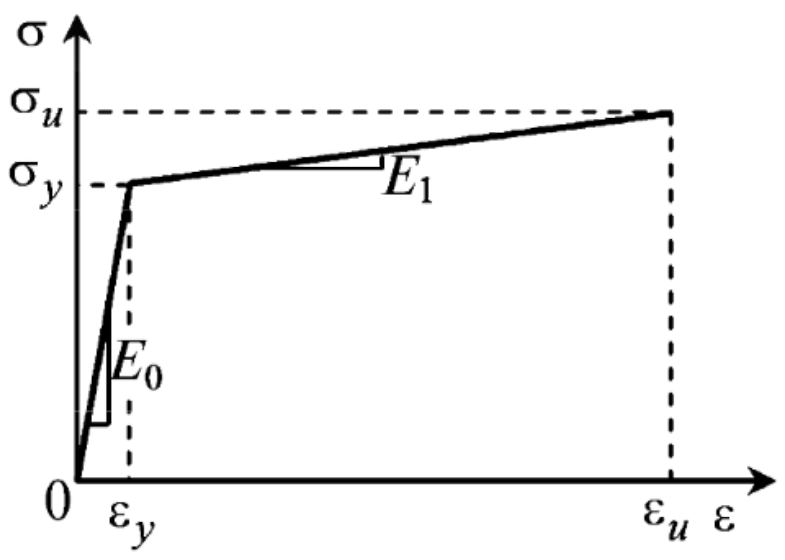

$E_{0}$ - modulus of elasticity of steel; $E_{1}-$ tangent modulus in the area of elastoplastic deformation; $\sigma_{y}$ and $\varepsilon_{y}$ - stress and deformation of the transition point to the section of elastoplastic deformation; $\sigma_{u}$ and $\varepsilon_{u}$ - stress and strain corresponding to the ultimate strength of the steel pipe material.

Fig. 3. Diagram of uniaxial tension of steel during deformation in the annular direction.

The problem of determining the value of the flow stress has not been solved. In the literature specific values are given for various steel grades and defect shapes. There is no theoretical dependence, and the magnitude of the flow stress is determined, as a rule, experimentally.

Since the stress intensity is the reduced intensity of shear stresses, expressed in terms of the equivalent normal stress in simple tension, i.e. equivalent tensile stress, then the following system is valid:

$$
\left\{\begin{array}{l}
\varepsilon_{i s}=\frac{2 \sigma_{i s}}{3 E_{0 s}}\left(1+2 v_{0 s}\right) \text { при } \sigma_{i s} \leq \sigma_{y}, \\
\varepsilon_{i s}=\frac{\sigma_{i s}-\sigma_{y}}{E_{1 s}}+\frac{\sigma_{y}}{E_{0 s}} \text { при } \sigma_{i s}>\sigma_{y} .
\end{array}\right.
$$

The tangent modulus of elasticity E1s according to the simplified diagram is numerically equal to the tangent of the angle of inclination of the tangent drawn from the point of yield to the point of break, and is calculated by the following formula [8]: 


$$
E_{1 s}=\frac{\sigma_{u}\left(1+\frac{\delta}{100}\right)-\sigma_{y}}{\ln \left(1+\frac{\delta}{100}\right)-\varepsilon_{y}},
$$

where $\delta$ - the relative elongation.

The anisotropic material of the band presumes different properties in different directions. According to the rule of mixtures, the values of Young's modulus are found along and across the fibers [9]:

$$
\left\{\begin{array}{l}
E_{L}=E_{f} V_{f}+E_{m}\left(1-V_{f}\right), \\
E_{T}=\frac{E_{f} E_{m}}{E_{m} V_{f}+E_{f}\left(1-V_{f}\right)},
\end{array}\right.
$$

where $E_{L}$ - Young's modulus of a conventionally homogeneous anisotropic composite material along the fibers, $\mathrm{MPa}$;

$E_{T}$ - Young's modulus of a conventionally homogeneous anisotropic composite material across the fibers, $\mathrm{MPa}$;

$E_{f}$ - Young's modulus of fiber filler, MPa;

$E_{m}$ - Young's modulus of matrix, $\mathrm{MPa}$;

$V_{f}$ - volumetric content of fiber filler, MPa;

$V_{m}$ - volumetric content of matrix, MPa;

Poisson's ratio can also be calculated according to the rule of mixtures in the direction along the fiber, and in the transverse direction, provided that the material is orthotropic according to the ratio between Young's moduli and Poisson's ratios [9], [10]:

$$
\left\{\begin{array}{l}
v_{T L}=v_{f} V_{f}+v_{m} V_{m}, \\
v_{T L} E_{L}=v_{L T} E_{T},
\end{array}\right.
$$

where $v_{L T}$ - Poisson's ratio for direction along the fiber; $v_{T L}$ - Poisson's ratio for direction across the fiber;

$v_{f}$ - Poisson's ratio of fiber filler;

$v_{m}$ - Poisson's ratio of matrix.

Ultimate pressure that the pipeline can experience in the presence of a defect, MPa [11]:

$$
P_{u}=\frac{\sigma_{m} t_{s}}{R} \cdot \frac{A_{0}-A}{A_{0}-A \cdot M^{-1}},
$$

where $\sigma_{m}$ - the yield point, with a bilinear stress-strain relationship, we take $\sigma_{m}=\sigma_{y}$, MPa;

$R$ - pipe radius, $\mathrm{m}$;

$A$ - area of metal loss on the projection of the defective area in the longwise section of the pipe wall, $\mathrm{mm}^{2}$;

$A_{0}$ - initial (without corrosion) area of the longwise section of the pipe wall along the length of the defective section, $\mathrm{mm}^{2}$;

$M$ - Folias factor.

To assess the stress-strain state of the pipelinebandage system, it is also necessary to determine the factory test pressure (the corresponding formula is given in [7]). The smallest of the defined pressures (factory test or limit for a pipe with a defect) is taken for calculation.
The calculation is done using numerical methods.

Let us evaluate the adequacy of the presented calculation method for various materials of the band. The mechanical mark on the outer surface of the pipeline metal was chosen as a defect. Such a defect is classified as "short".

The rest of the initial data for the calculation are shown in Table 1.

Table 1. Initial data.

\begin{tabular}{|l|c|}
\hline Pipeline diameter $D, \mathrm{~mm}$ & 1220 \\
\hline Wall thickness $t_{s}, \mathrm{~mm}$ & 20 \\
\hline Tension force of roll materials $N, \mathrm{kN} / \mathrm{m}$ & 1.472 \\
\hline Internal pressure in the pipeline $P, \mathrm{MPa}$ & 7.5 \\
\hline Tensile strength of steel $\sigma_{u s}, \mathrm{MPa}$ & 550 \\
\hline Yield strength of steel $\sigma_{y s}, \mathrm{MPa}$ & 410 \\
\hline
\end{tabular}

To put that into perspective, we present the calculation results in the form of a graph, Figure 4, showing the dependence of the thickness of the band on the selected material at different values of the stress concentration factor:

- tensile strength of the band from 100 to $1600 \mathrm{MPa}$;

- stress concentration factor from 1.5 to 3.5 .

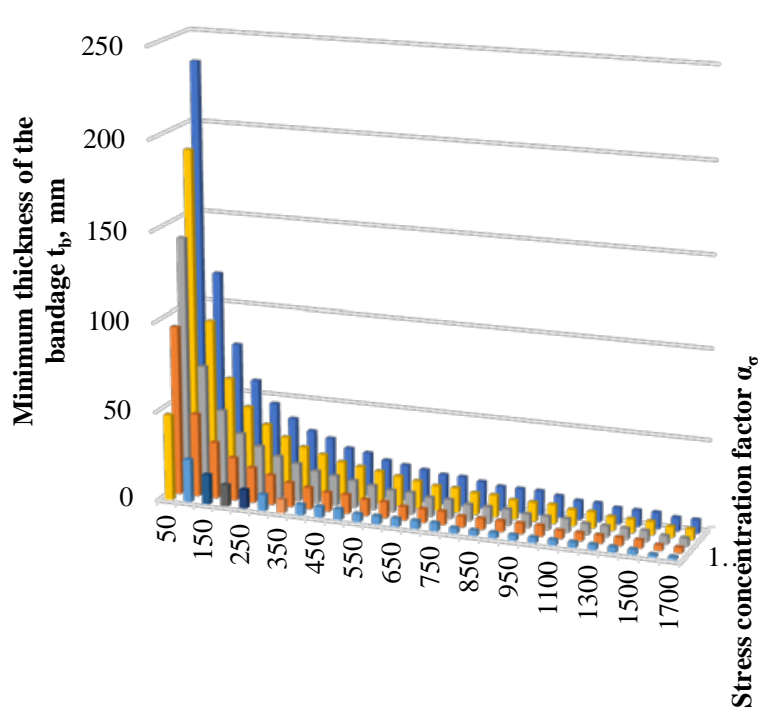

Breaking stress of the band, MPa

Fig. 4. Dependence of the thickness of the band on the selected material at different values of the stress concentration factor.

Based on the Figure 4, it can be argued that it is preferable to use materials with a tensile strength of $200 \mathrm{MPa}$ or more.

The obtained values of the minimum thickness of the band can find practical application for the known values of the ultimate strength of the band. For this purposes the polymer materials on the market used for pipeline repairs 
were analyzed. The characteristics of the materials are presented in Table 2.

Table 2. Specifications of materials.

\begin{tabular}{|l|c|c|c|}
\hline Material & $\begin{array}{c}\text { Tensile } \\
\text { strength, } \\
\text { MPa }\end{array}$ & $\begin{array}{c}\text { Young } \\
\text { modulus }\end{array}$ & $\begin{array}{c}\text { Poison's } \\
\text { ratio }\end{array}$ \\
\hline $\begin{array}{l}\text { Carbon fiber (tape) } \\
\text { of JSC «Kompozit» }\end{array}$ & 900 & 150 & 0.265 \\
\hline $\begin{array}{l}\text { Organoplastic of } \\
\text { JSC «Kompozit» }\end{array}$ & 1600 & 80 & 0.34 \\
\hline $\begin{array}{l}\text { Fiberglass of JSC } \\
\text { «Kompozit» }\end{array}$ & 600 & 50 & 0.28 \\
\hline $\begin{array}{l}\text { Fiberglass (epoxy } \\
\text { polymer 5-211B } \\
\text { and E glass) }\end{array}$ & 200 & 24.26 & 0.15 \\
\hline CHT & $350 \div 684$ & $21.6 \div 28.0$ & 0.3 \\
\hline EARF & $950 \div 1390$ & $24.8 \div 52.0$ & 0.3 \\
\hline EARF-2 & 600 & 38 & 0.3 \\
\hline ERF 900 & 52 & 0.3 \\
\hline COT-301-1 Spring» & 900 & 38 & 0.3 \\
\hline $\begin{array}{l}\text { «Clock } \\
\text { Cuffs }\end{array}$ & 460 & 21.7 & 0.28 \\
\hline $\begin{array}{l}\text { Fiberglass VPS- } \\
\text { 53/120 }\end{array}$ & 12 & 0.2 & 0.4 \\
\hline Tape «Polyterm» & 620.5 & 34.4375 & 0.4 \\
\hline $\begin{array}{l}\text { «WrapMaster» cuff } \\
\text { material }\end{array}$ & &
\end{tabular}

\section{Conclusion}

The present study leads us to the following conclusions:

1. Out of a number of materials being studied here, only «Polyterm» tape was unable to provide the normal operation of the pipeline system with a reasonable thickness of the bandage layer. The bandage material should be selected based on the rational choice of the minimum wall thickness and the material properties, with tensile strength being the main one;

2. The advantages of the repair using the banding method include the absence of restrictions on the diameter, length and operating pressure of reinforced pipelines;

3. The calculations of the stress-strain state of the bandage should be done using properly chosen the «bandage-pipe» design scheme

4. For the full use of the material, it can be recommended to consider the stress state of the band with taking into account the elastic-plastic behavior of its material;

5. The possibility of using of a bandage for repairing defects should be determined based on capabilities of machines being used and the analysis of the prior use of the bandage for repairing defects with known stress concentration factors.

\section{References}

1. RD 153-39.4-067-04, Methods for repairing defective working oil trunk pipelines (JSC AK Transneft, 2004)
2. I.N. Budilov, G.V. Kulyasov, Yu.V. Lukashchuk, V.V. Shevela, Bulletin of USATU, 1(54), 57-62 (2013)

3. S.A. Korneev, I.V. Krupnikov, S.N. Polyakov, V.V. Shalai, Omsk Scientific Bulletin, 1(87), 48-51 (2010)

4. A.A. Bauer. V.M. Kushnarenko, A.E. Pyataev, Yu.A. Chirkov, D.N. Shchepinov, OSU, (2015)

5. E.A. Lobova, D.A. Gulin, R.A. Fazletdinov, R.R. Musalyamov, Transport and Storage of Oil Products and Hydrocarbons, 1 (2018)

6. S.K. Rafikov, G.S. Sharnina, M.M. Fattakhova, Calculation of the residual resource of oil pipelines by low-cycle durability of steel pipes (USPTU, 2011)

7. SP 36.13330.2012. Trunk pipelines (Moscow, 2013)

8. V.A. Vasiliev, A.V. Samoshin, Measurement. Monitoring. Management. Control, 3(21), 108-114 (2017) DOI: $10.21685 / 2307-5538-2017-3-15$

9. A.S. Milenin, E.A. Velikoivanenko, G.F. Rozynka, N.I. Pivtorak, Collection of reports of the VII international conference. (Kiev, 2014)

10. A.A. Smerdov, Herald of the Bauman Moscow State Technical University. Series Mechanical Engineering, 1, 52-60 (2011) ISSN 0236-3941

11. A.A. Filatov, V.I. Kochetov, I.I. Veliyulin, R.R. Khasanov, Neftegaz Territory, 40, 68-72 (2018)

ISSN 2072-2745 